\title{
Analysis on the Social Security System of Retired Athletes in China
}

\author{
Keqing Sheng \\ Wuhan University of Science \& Technology \\ Wuhan, China 430065
}

\author{
Wenyu Wang \\ Wuhan University of Science \& Technology \\ Wuhan, China 430065
}

\begin{abstract}
With the social transformation, especially the deepening of reform, athletes security system has undergone profound changes. With the disintegration of the original national security system and the failure of the new social security system of athletes, the rights of some athletes have not been effectively protected. And some of them even have the difficulties in lives. Then it attracts the social concern on the social security of athletes. From these perspectives, the studies analyze the necessity of establishing the social security system of retired athletes, discuss the components of the social security system of retired athletes, and put forward some suggestions on some specific problems.
\end{abstract}

Keywords-retired athletes; social security; retirement replacement

\section{INTRODUCTION}

Before the reform and opening up, China's social security system adopts the mode of national security. In the mid1980s, with the reform of the urban economic system and the development of the market economy, it had reformed the social insurance system, which focused on endowment insurance, medical insurance and unemployment insurance. And then the responsibilities of the social security system begin to be shared by the state to the government, units and individuals. In the era of planned economy, the social security of athletes in China can be divided into two parts. The first is that the state is responsible for active athletes in national sports team. The second is that the units are responsible for the retired athletes. In other words, the various rights of athletes can be guaranteed whether it is protected by the state or the units. With the deepening of reform, the social security system of athletes is also changed from state-unit system to state-society system. During the period of system transition, some excellent athletes such as Dai Guohong, Cai Li, Zou Chunlan, Ai Dongmei and other famous athletes have difficulties in lives after retirement. Also, some athletes such as Sang Lan are hurt heavily in the games. After being widely reported by the media, the social security issues of athletes cause the social concerns.

\section{THE STATUS OF ATHLETES AFTER RETIREMENT}

\section{A. The Status of Foreign Athletes after Retirement}

1) America: In the United States, the education and training system are relatively perfect and rich. Due to the support of relevant social security systems, those amateur athletes who can't find a job after retirement can solve the most basic food and clothing problems when they are in temporary unemployment. And there is a relatively sound social security system. The social security system of the United States relies on all kinds of insurance. As long as the athletes meet the payment period and premium and other conditions, they can get the basic guarantee of the life in a specific period. American athletes are divided into professional athletes and amateur athletes. Professional athletes generally have a more generous annual salary. And they can guarantee the basic food and clothing in a period of retirement. The purpose of amateur athletes to participate in sports is not to feed their families, and most of them have their own jobs or expertise. When time, physical fitness and energy are coordinated, they would leave their jobs or change their work plans to fully engage themselves in the training game. Once they found that they were out of it, and then they would give up the training and continue to engage in their own works. In addition, the education system in the United States ensures that all educatees can acquire basic knowledge and certain skills to lay the foundation for them to do a job in the future.

2) Japan: Japan's professional system has been improved in recent years. In addition to a few sports such as baseball, soccer and golf, the proportion of professional athletes is not high. And most people have to complete the education curriculum. It also makes them to have the basic skills to have a foothold in society after giving up sports. Japan retrains the retired athletes and helps them integrate into society as quickly as possible. Japan offers a job as a coach for those who have excellent performance in the original sports. The Japanese government has also discussed that they should make some compensation to the athletes in some ways. However, in general, the Japanese athletes are basically able to fend for themselves after the 
retirement. After the age of 60 , they can also enjoy high pension benefits and maintain a comfortable life.

3) Russia: In recent years, the tragic life of the retired athletes is reported on the news frequently. Russia is a sports country and has cultivated a large number of outstanding athletes. However, Russia lacks the relevant security systems for athletes, and most of athletes will face the problem of self-employment after the retirement. The embarrassing situation of retired athletes in re-employment has not received the general attention of Russian society for a long period of time. And it has become a difficult problem for many athletes.

\section{B. The Status Quo of Chinese Athletes after Retirement}

In the planned economy, the resettlement of retired athletes is relatively smooth. And the personnel departments and labor departments will properly accommodate for the placement of official players. Since 2002, with the development of professionalization and the expansion of the club system, the regulations on the distribution of retired athletes are subsequently cancelled by the state. Nowadays, with the reform of government organs and enterprises and institutions, their personal autonomy is gradually expanding. The relevant entry threshold is higher and higher, and the problem of placement of athletes is becoming more and more prominent. In recent years, some early retired athletes don't get the jobs in retired period. And they don't receive the relevant preferential treatment and pension allowance. So they have to engage in the heavy manual labour. Even some athletes are forced to beg on the street after being discriminated against by society in reemployment. It reflects the imperfect aspects of China's civil society security system.

On the retirement of the athletes, the state doesn't have unified placement requirements. And the unified provisions of the state are to make the initial protection - the retirement payments. The general way is to make one-time economic compensation based on factors such as the sports life of athletes, competition results and pre-retirement allowance. And then, the athletes can choose the jobs independently. However, social competition is becoming more and more intense. And it is obvious that there is a disadvantage in the employment of competitive sports. It is obvious that the athletes who only have skills in competitive sports have no advantages in employment. At present, the overall characteristics of the living status of retired athletes in China can be divided into several concepts. For example, the big gap between the wealthy and the poor, the disintegration of the status, and serious imbalance in survival and development. Some people have been accustomed to comparing the Chinese competitive sports to pyramid structure. The athletes at the spire aren't generally worried about the ways to survival. And most of the athletes in basic strength have weak safeguards.

\section{ANALYSIS ON THE RETIRED ATHLETES' PROBLEMS IN THE SOCIAL SECURITY SYSTEM OF CHINA}

Athletes' social security is organized measures, policies and systems. According to certain laws and regulations, the state raises social funds in a certain way. Through the reallocation of income, it gives compensation to the athletes who have the risks such as disability, disease, retirement, unemployment and other risks. The temporary or permanent loss of movement (work) may cause their loss of income. And then, these athletes may have difficulties in life. Then, the athletes can get the basic guarantee of the life through the athlete social security.

With the development of the socialist market economy and the reform of the national social security system, the social security system of the athletes is also facing great challenges. The security system, legislation, supervision, management mode and other aspects no longer meet the needs of the present. It should be continuously improved.

\section{A. The Social Security System of Retired Athletes Needs to be Improved}

In general, in terms of pension, disability or employment insurance, the protection of Chinese athletes needs to be improved. First of all, for the endowment insurance, the athletes' insurance is in accordance with the staff's insurance in personnel at present. The insurance is paid by the states. And this practice is consistent with the practice before reform. However, the athletes can not enjoy the corresponding treatment once they have been resettled in the administrative institutions or public institutions after their retirement. What the athletes need most is the disability insurance. In 1998, China has established the sports injury insurance. After Sang Lan was fatally injured in the competition, the relevant systems have been improved. However, the establishment of the system hasn't taken into consideration of the different needs of athletes on the disability insurance in the different status. There are many problems in the actual operation. And it has caused the athletes' dissatisfaction. In the placement of the athletes, besides a very small number of particularly good athletes, they can be placed in government departments or institutions after retirement. A large number of retired athletes would stay in the team for a long time. And they can't find a stable career to get through the transition. It not only makes many retired athletes face the life difficulties, but also seriously affects the development of our sports.

\section{B. The Legislation of the Athletes' Social Security System Is Low and Inadequate}

At present, the legal basis of the social security system of athletes in China can be divided in the following categories. The first is the department regulations issued by the State Sports General Administration. For example, in 2003, the State Sports General Administration developed the "Temporary measures for the implementation of the care fund of the old athletes and coaches in national team". The second is the department regulations issued by the State Sports General Administration, Ministry of Personnel, Ministry of Public Security, Ministry of Finance, Ministry of Labor and Social Security, Ministry of Education and other departments. For example, the "Interim Measures for the recruitment of athletes" was developed in 2007. In general, the current level of legislation on athlete social security is low. And it is mainly focused on the department regulations. The authority is not enough. 
In addition, in the existing rules and regulations, the athlete social security is not in place. For example, the athlete's disability insurance is mainly the "Excellent Athlete Disability Mutual Insurance". The insurance is operated by All-China Sports Foundation commissioned by the General Administration of Sports. And it is limited to the active outstanding athletes in the team. Also, it has the "accidental injury insurance" to protect the active athletes participating in the events, which is insured by the Organizing Committee of the event. The insurance hasn't taken into consideration of the delay of athlete disability. It hasn't taken consideration of the compensation for the delay of athlete disability after retirement. The third is the employment injury insurance issued by the provincial professional team for the athletes. The compensation standard of insurance is very low. Even if they have got the specific disability, they would get less than a thousand yuan of subsidies each year. And it can't achieve the protection. In summary, there are three types of insurance. However, the first type of insurance is limited to the insured. The second insurance is limited to the insurance time, and the third type of insurance is limited to the amount of insurance. At present, it is lack of the legislative protection to the athletes.

\section{The Athletes' Social Security Is Not Adequately Supervised by the Management Department and the Service Is Vacant}

The improved athlete system not only includes the norms of system and the strengthening of the law, but also includes good systems to implement the social security services and the sound regulatory systems. However, the official mentality has been existed for a long time. Many management department of athlete social security doesn't have the consciousness of initiative service. And athletes in the enjoyment of their own security need to deal with a lot of complicated and trivial administrative affairs. It affects the follow-up works of the athletes' social security. In the aspect of policy supervision, the endowment insurance and other minor protection projects are in the strict supervision with the development of the policy. And the construction of supervision system and service system of other security project needs to be improved. For example, the operation of social security funds, work injury prevention and rehabilitation, disability protection, the placement of the retired athletes and other aspects, etc. And there have been policy loopholes in supervision. Then the 20 million yuan sports insurance fund of China Sports Fund was cheat in 1997.

\section{The Management Model of Athletes Social Security \\ Needs to Make a Transformation}

There are many problems in the old management model of athlete social security. The management is not smooth, and athletes are not satisfied with this management model. For example, the athletes in different levels are managed by different departments. And the security standards are also different. In fact, it is contrary to the principle and purpose of social security and social co-ordination. It is not conducive to the formation of social harmony. In addition, the management of athletes is in more stringent control, which is not conducive to the development of their own work, but also not conducive to the mobilization of local enthusiasm. It can't really achieve the management according to the local conditions. Finally, there is no distinction between government and administration. It is one of the reasons why the sports administration is deeply plagued by management. The makers and performers of policy, the policy performers and financial distributors are the same administrative subjects. It is obviously not conducive to the development of management and supervision work. In general, the current social security environment in China is transformed from the administrative security to the social security. Athlete social security is no exception. It must achieve the transformation of model. And then, it will get the sustainable development.

\section{THE COUNTERMEASURES AND SUGGESTIONS FOR IMPROVING THE SOCIAL SECURITY SYSTEM OF RETIRED ATHLETES IN CHINA}

Facing the new situation, it should improve the overall strength of our athletes with the changes of the environment. It should pay attention to the development and improvement of our athletes' security system. On the athlete security system, legislation, management system and other issues, it puts forward the following countermeasures.

\section{A. To Construct a Complete Social Security System for Athletes}

For the endowment insurance, the government needs to make a transformation from personal partiality security of athletes to social ordinary pension security. According to the regulation of the system, it should avoid the blank of athlete security at the end of the sports career. The disability insurance should be the top priority of athletes' social security. In this term, the first thing is to establish special athlete disability identification agencies. And it also should develop the appropriate standards to ensure the authenticity of the agency. So the agencies can effectively protect the interests of athletes. Secondly, it should use the network information technology to establish the athlete injury information database. The information base covers the physical functions of the athletes in different stages since the beginning of the training, the causes of injury, and the causes of disability, follow-up treatment regimens, and feedback and tracking of treatment outcomes. It is conducive to clear responsibility. And it also provides a basis for the coaches to develop a scientific training program. Thirdly, it should learn foreign skills and experiences. And it can make the targeted insurance for the athletes flexibly. The actual protection of athletes can be achieved in the case of disability. Finally, what the athletes need most is the placement of employment. Firstly, the government should set up a reemployment agency for retired athletes. This institution will carry out vocational skills training for their specialties to achieve the smooth docking with the community after the retirement. Secondly, it must create a good policy environment for athletes to start their own businesses. For example, it can establish appropriate tax relief system and loan concessions, and so on. Finally, the relevant study system for the retired athletes can be established to make up for the deficiency of cultural knowledge. And it can lay a good foundation for the follow-up career. 


\section{B. To Strengthen the Construction of the Legislative System}

The establishment of a sound legislative system is of great benefit to the promotion of athletes' social security. First of all, the government should promote the relevant legislation on the social security of athletes to achieve the transition from the current administrative legislation to the NPC-legislation, and improve the level of social security legislation. In addition, it should improve the scientific nature of legislation and the comprehensive protection. In terms of personnel, it should not only protect the elite athletes, but also protect the grassroots and general athletes. And then, coaches and volunteers who participate in the event activities should also be included in the scope of protection. It should achieve the protection as far as possible. In the term of security time, it must establish the subsequent disability protection in the legislative level after the athletes' retirement. Because of the injuries in the sports career, it should achieve the continuity of protection. In terms of the insurance amount, the insurance amount should develop with the increase of social living standard. In the protection of disabled or retired athletes' basic living, it should also raise funds through a variety of channels to establish athletes living security funds. It can ensure that disabled or retired athletes can enjoy the social welfare and treatment.

\section{To Establish a Sound Regulatory System and Improve the Service System}

First of all, it should make personnel training for the specialized management, change their working concept, and effectively improve their awareness of social services. At the same time, it should re-sort out the scope and content of the work. And then, it can establish the employment placement guidance agencies for the retired athletes. Also, they should establish their own service concept. Secondly, the third-party athletes guarantee fund regulators should be established to ensure that the relevant regulatory agencies have the relevant basis when they give out penny and spend every penny. It should severely punish the units and individuals who abuse the funds to ensure the safety of social security funds. In addition, they must have self-examination on the existence of regulatory loopholes. It should avoid the loss of fund loss or fraud from the original source. And then, it may prevent the regulatory loopholes.

\section{To Explore a Sound Management System}

First of all, it should achieve the national co-ordinated universal social security of all the athletes. So the coordination funds may play the effectiveness of mutual aid and mutual assistance. At the same time, it introduces a social management model, and should learn and adopt the market-oriented approach. Then, it may reduce the rentseeking corruption of government in the regulation and inefficiency as far as possible. Secondly, it should make many things according to local conditions. It should make a combination between the state's proper decentralization and local subjective initiative to enable local institutions to carry out their athletes' social security flexibly according to their own conditions. Again, commercial insurance should be encouraged to enter into athletes' protection. If the state can't carry out the protection of athletes in some conditions, it can provide additional protection. Finally, it should establish a reasonable and perfect insurance fund raising mechanism to realize the multi-pillar financing mode of the state, society and individual.

\section{CONCLUSION}

The establishment of athlete's social security system allows athletes to obtain better material life after retirement. Also, it can make the active athletes and the sports groups ready to join in the sports become the driving force to promote the development of sports in China without worries. In addition, the establishment of athletes' social security system can show the government's care and love for special groups. And it is one of the necessary conditions for the establishment of a harmonious society. With the government's strong advocacy and the introduction of relevant supporting policies, China's athlete social security will be better and better.

\section{REFERENCES}

[1] Zheng Gongcheng. Social Security [M]. Beijing: Commercial Press, 2000.

[2] Pan Jintang. Introduction to Social Security [M]. Beijing: Beijing Normal University Press, 2012,220.

[3] Zou Dexin. Research on the Changes of Athletes' Social Security System [J]. Journal of Shenyang Physical Education Institute, 2010 (3).

[4] Zhang Ruihua. Protection of Elite Athletes in Australia and New Zealand and Its Implications [J]. Journal of Sports Culture, 2008 (11): 114-115

[5] Cai Xiaowei. Research on the social security legal system of Chinese athletes [J]. Journal of Beijing Sport University, 2004 (7): 872-874

[6] Liu Fengting. Reflection on the construction of legal system of China 's athletes social security management system [J]. Sports and Science, 2006 (4)

[7] Huang Xiaoling. Research on the social security system of athletes [J] Journal of Beijing Sport University, 2010 (5): 13-16.

[8] Wu Hongluo, Zhang Guoshu. Analysis on the endowment insurance of retired athletes $[\mathrm{J}]$. Journal of the Fujian Provincial Committee Party School, 2008 (4): 66-69.

[9] Zou Dexin. A Study on the demands of social endowment insurance of athletes $[\mathrm{J}]$. Journal of Shenyang Physical Education Institute, 2009 (1): 10-13.

[10] He Ping. The difficulties and Countermeasures of employment of retired athletes in China [J]. China Sports Science and Technology, 2008 (3): 10-15.

[11] Meng Fanqiang. The deficiency of re - employment of China 's retired athletes and countermeasures [J]. Journal of Nanjing Institute of Physical Education, 2009 (1): 69-72.

[12] Wang Xiuxiang. Investigation and analysis on disability of Chinese athletes [J]. Journal of Liaoning Normal University (Natural Science Edition), 2007 (2): 39-44

[13] Zou Guozhong, Chen Shaocheng. Research on the current education of the elite athletes and the optimization of the construction of social security in China [J]. Journal of Nanjing Institute of Physical Education (Social Science Edition), 2010 (3): 95-99.

[14] On Further Strengthening the Social Security of Athletes issued by the State Sports General Administration, the Ministry of Finance, the Ministry of Labor and Social Security [R]. 2006.

[15] On further strengthening the athlete cultural education and the guidance of the notice issued by General Office of the State Council forwarded the General Administration of Sports and other departments [R]. 2006. 